\title{
Craniodental traits and interaction in the bite force of tropical frugivore bats (Phyllostomidae: Stenodermatinae)
}

\author{
Leidy García Herrera ${ }^{1}$, Leidy Ramirez Francel ${ }^{1}$, Giovany Guevara ${ }^{1}$, Gladys Reinoso Florez \\ ${ }^{1}$, Alfonso Sánchez Hernández ${ }^{1}$, Burton Lim $^{2}$, and Sergio Losada prado ${ }^{1}$ \\ ${ }^{1}$ Universidad del Tolima \\ ${ }^{2}$ Royal Ontario Museum
}

January 29, 2021

\begin{abstract}
1. Phyllostomid bats exhibit great diversity in skull size and morphology that reflects the degree of resource division and ecological overlap in the group. In particular, Stenodermatinae has high morphological diversification associated with cranial and mandibular traits that is associated with the ability to consume the full range of available fruits (soft and hard). In terms of morphology, performance (bite force) appears to play an important role in niche partitioning among bat species, however, very few studies have confirmed these relationships using functional cranial traits. 2. Here, we analyzed craniodental traits and their relationship to the bite force in 308 specimens distributed in seven species of stenodermatine bats with two foraging types: nomadic and sedentary frugivorous bats. We evaluated 19 functional traits of the skull and jaw related to feeding and bite force in live animals by correcting bite force with body size. We used a GLM model and post hoc tests to determine possible relationships and differences between cranial traits, species, and sex. 3. The results showed that there is significant interspecific variation between stenodermatines that are nomadic and sedentary. The greatest variation in bite force within species was explained by the mandibular toothrow length (MANDL) between sexes, which was greater in females. The larger species of Artibeus, together with Platyrrhinus helleri, Uroderma convexum and Sturnira giannae, which have a greater length of the skull, condylo-incisor, condylo-canine, mandibular toothrow and height of the coronoid, exhibit greater bite force. By contrast, the smaller species A. anderseni and A. phaeotis have short skulls and the lowest values of bite force, which suggests that the size of the skull confers a biomechanical advantage. 4. Our results highlight the usefulness of analyzing functional traits related to feeding to establish the performance of bats in terms of the bite force.
\end{abstract}

\section{Craniodental traits and interaction in the bite force of tropical frugivore bats (Phyllostomidae: Stenodermatinae)}

Leidy Viviana García Herrera ${ }^{1 *}$, Leidy Azucena Ramírez-Fráncel ${ }^{1}$, Giovany Guevara ${ }^{2}$, Gladys ReinosoFlórez ${ }^{2}$, Alfonso Sánchez-Hernández ${ }^{3}$ Burton K. Lim ${ }^{4}$, Sergio Losada-Prado ${ }^{2}$

${ }^{1}$ Programa de Doctorado en Ciencias Biológicas \& Grupo de Investigación en Zoología (GIZ), Facultad de Ciencias, Universidad del Tolima, Altos de Santa Elena, Ibagué, Colombia.

${ }^{2}$ Departamento de Biología \& Grupo de Investigación en Zoología (GIZ), Facultad de Ciencias, Universidad del Tolima, Altos de Santa Elena, Ibagué, Colombia.

${ }^{3}$ Departamento de Matemáticas y Estadística, Facultad de Ciencias, Universidad del Tolima, Altos de Santa Elena, Ibagué, Colombia.

${ }^{4}$ Department of Natural History, Royal Ontario Museum, 100 Queen's Park, Toronto, Ontario M5S 2C6, Canada. 
*Corresponding authorlvgarcia@ut.edu.co

\section{Abstract}

1. Phyllostomid bats exhibit great diversity in skull size and morphology that reflects the degree of resource division and ecological overlap in the group. In particular, Stenodermatinae has high morphological diversification associated with cranial and mandibular traits that is associated with the ability to consume the full range of available fruits (soft and hard). In terms of morphology, performance (bite force) appears to play an important role in niche partitioning among bat species, however, very few studies have confirmed these relationships using functional cranial traits.

2. Here, we analyzed craniodental traits and their relationship to the bite force in 309 specimens distributed in seven species of stenodermatine bats with two foraging types: nomadic and sedentary frugivorous bats. We evaluated 19 functional traits of the skull and jaw related to feeding and bite force in live animals by correcting bite force with body size. We used a GLM model and post hoctests to determine possible relationships and differences between cranial traits, species, and sex.

3. The results showed that there is significant interspecific variation between stenodermatines that are nomadic and sedentary. The greatest variation in bite force within species was explained by the mandibular toothrow length (MANDL) between sexes, which was greater in females. The larger species of Artibeus, together withPlatyrrhinus helleri, Uroderma convexum andSturnira giannae, which have a greater length of the skull, condylo-incisor, condylo-canine, mandibular toothrow and height of the coronoid, exhibit greater bite force. By contrast, the smaller species A. anderseni and A. phaeotis have short skulls and the lowest values of bite force, which suggests that the size of the skull confers a biomechanical advantage.

4. Our results highlight the usefulness of analyzing functional traits related to feeding to establish the performance of bats in terms of the bite force.

\section{KEYWORDS}

Ecomorphology, frugivores, morphometry, Stenodermatinae, skull, trophic performance.

\section{INTRODUCTION}

The skull of vertebrates is a complex assembly that is closely related to the resource collection, food processing, behavior, and ecology of the species (Bels \& Herrel, 2019). Examining the patterns and mechanisms that lead to cranial variation, including shape and traits, enables an understanding of the morphology, ecology, and general fitness of animals (Santana, Dumont, \& Davis, 2010). Bats have variation in cranial morphology attributed to evolutionary processes of ecological specialization, which result in a niche division between ecomorphologically similar species (Santana, Grosse, \& Dumont, 2012). This variation responds mainly to functional requirements related to nutritional performance and the sensory system (Thiagavel et al., 2018).

Among chiropterans, New World leaf-nosed bats (Phyllostomidae) represents one of the largest and most morphologically diverse mammal families (Rossoni et al., 2017). Ecological diversification in Phyllostomidae is related to bite performance and mechanical demands of different diets, including frugivores, insectivores, nectarivores, carnivores, and sanguinivores (Dumont, 2007, Nogueira, Peracchi, \& Monteiro, 2009; Manhães, Nogueira, \& Monteiro, 2017). Dietary differences require specific mechanical modifications, including variation in the rostral length and height of the skull (Santana, Dumont, \& Davis, 2010). However, there is a lack of understanding about the patterns in the variation of the shape and performance (López-Aguirre \& Pérez-Torres, 2015). The remarkable specializations seen in these bats provide a unique opportunity for studying the relationship between cranial morphology, feeding performance, and dietary ecology (Aguirre, Herrel, Van Damme, \& Matthysen, 2002; Rossoni et al., 2017).

The bite force is a biomechanical trait that determines various vital functions, such as feeding, mating, defense, and competition, and is closely related to body size and feeding performance (Santana, Dumont, \& Davis, 2010). Therefore, an increase in bite force allows for a broader spectrum of food available (Santana \& Dumont, 2009). Phylostomid exhibit bite forces associated with the size and hardness of food (Aguirre, Herrel, 
Van Damme, \& Matthysen, 2003), resulting in strong morphological heterogeneity due to the particularities of the diet (Dumont \& O'Neil, 2004).

Although various studies have addressed the relationships of craniodental morphology, bite force and diet (e.g., Aguirre, Herrel, Van Damme, \& Matthysen, 2002; Dumont, Herrel, Medellín, Vargas-Contreras, \& Santana, 2009: Santana, Grosse, \& Dumont, 2012; Santana \& Miller 2016), the evaluation of these variables has been carried out separately, evaluating each variable independently (Shi et al., 2020). Likewise, the information related to the craniodental traits responsible for generating bite forces in bats is limited without much attention to the functionally relevant components of the craniodental system and the musculature of the jaw (Herrel, Smet, Aguirre, \& Aerts, 2008). The specific hardness of food and the bite force required to process food play an important role in the division of resources within frugivore bat communities (Dumont, 2007). According to Soriano (2000) and Giannini \& Kalko (2004), fruit bats can be categorized as nomadic or sedentary, with preference for a specific type of plant, morphological diversity reflected in the physical properties of the fruits, and a tendency of specialization towards a specific fruit or group of fruits (Santana, Dumont, \& Davis, 2010; Santana, Grosse, \& Dumont, 2012).

Frugivorous bats provide an excellent model to study the relationship between craniodental morphology and bite force because they consume both hard and soft fruits, the result of adaptive pressures related to mandibular morphology (see Murillo-García, \& De la Vega, 2018). We selected the members of the family Phyllostomidae due to the fact that they have the highest diversity of mammals with more than 70 species that are found sympatrically and serve as nocturnal predators, pollinators and predominant seed dispersers (Giannini \& Kalko, 2004; Reid et al., 2015), and within this family, the Stenodermatinae subfamily, contains $>43 \%$ of all described New World leaf-nosed bat species (Shipley \& Twining, 2020) and in central Colombia, department of Tolima, these chiropterans represent near the $13 \%$ in the sampled areas (see García-Herrera, Ramírez-Fráncel, \& Flórez, 2019).

Our objective was to identify the functional traits associated with bite force in seven representative species of the Stenodermatinae subfamily occurring in Colombia. We hypothesize that large species and small-sized nomadic frugivorous species with narrow faces, wide palates and shorter length between molars will have a greater biomechanical advantage of stronger bite force in relation to sedentary frugivorous bats.

\section{MATERIALS AND METHODS}

\subsection{Samples and classification}

From February 2019 to January 2020, we registered bite force and skull morphology data of seven species of Stenodermatinae fruit bats (Appendix I). These bats were divided into two categories: (i) nomadic frugivores:Artibeus anderseni, A. phaeotis, A. lituratus, A. planirostris, Platyrrhinus helleri, Uroderma convexum; (ii) sedentary frugivores:

Sturnira giannae.

\subsection{Field collection and laboratory analysis}

We follow two procedures for collecting our data: i) fieldwork in selected areas of the Colombian tropical dry forest-TDF in the department of Tolima (Figure 1, red triangle marks) using conventional methodology, i.e., mist-nets placed along trails within forest areas, at the edge of forest remnants, and near waterbodies. Each sampling night consisted of four standard size mist nets $(12 \times 2.5 \mathrm{~m})$, eight nets $(6 \times 2.5 \mathrm{~m})$ in the sub-canopy and a Triple High net $(30 \times 7 \mathrm{~m})$, with a sampling intensity of $36.288 \mathrm{~m}^{2}$ nets $/ \mathrm{h}$, corresponding to $864 \mathrm{~h}$ in 144 nights. The captured bats were handled according to the American Society of Mammalogists guidelines for the use of wild animals for research purposes (Sikes \& Animal Care and Use Committee of the American Society of Mammalogists, 2016). After capture, the age, sex, and reproductive status were evaluated, and only adult males and adult non-pregnant, non-lactating females were used for the measurements. Age and sex were identified based on the degree of ossification of the coat and tibia. Reproductive status in females was determined by examining the nipples and palpitation of the abdomen. Then, bats were put into cloth 
bags and transferred to measure the bite force using a portable digital fruit hardness tester (Lutron, Indian) with a capacity of 196.10 Newton and precision \pm 0.05 .

We follow the method of Freeman \& Lemen (2008), and bite force was recorded at the molars, measurements were repeated five times for each bat with an inter-trial interval of at least $5 \mathrm{~min}$. The maximum value of the five measurements was considered as the maximum bite force produced by that individual. The bite force of the species was calculated by averaging the maximum bite force of each individual. The captured specimens were used for direct measurements of the forearm length, body mass, then they were euthanized and handled for craniodental morphometry (Figure 2; see Table S1), and entry to biological collection of the University of Tolima CZUT-M (Ibague, Colombia). ii) The second procedure consisted of measurements of 16 craniodental traits and two body traits (Table 1, Figure 2) obtained of voucher specimens from the Zoological Collection of the University of Tolima (CZUT; Ibague, Colombia), Museo Javeriano de Historia Natural "Lorenzo Uribe, SJ" (MPUJ; Bogota, Colombia) and Royal Ontario Museum (ROM; Ontario, Canada). The revised specimens from these biological collections belong to 24 localities in Colombia (Figure 1; Appendix I). We verified that all adult specimens according to the ossification of the growth plates of the epiphysis of the phalanges of the fingers (Dietz et al., 2007).

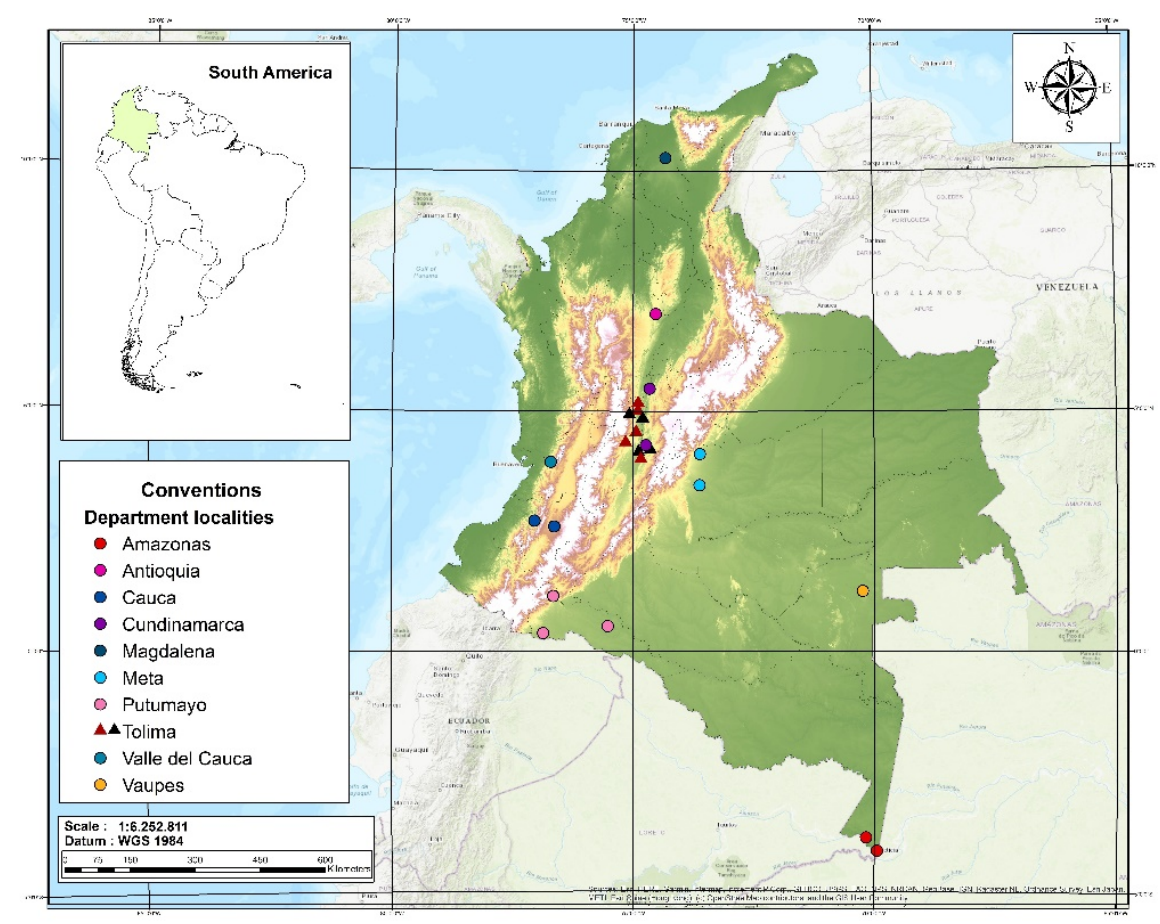

FIGURE 1 Geographic distribution of the locations of the Stenodermatinae bat samples used for the biometric analyzes. Triangle black marks represent sampling points where capture of Colombian Stenodermatinae bats was carried out in the department of Tolima; other circle marks represent records of other sampling sites obtained from voucher specimens (see text for more details).

TABLE 1 The craniodental, mandibular and external measurements used as functional traits in this study.

\begin{tabular}{lll}
\hline Variable & Main trait & Description \\
\hline Bite force & Head & Maximum bite force produced by molars \\
Forearm length & Body & Distance from the olecranon process to anterior surface of carpals in the folde \\
Mass & Body & Physical quantity that allows to indicate the quantity of matter contained in
\end{tabular}




\begin{tabular}{lll}
\hline Variable & Main trait & Description \\
\hline Greatest length of skull & Head & Distance from the posterior-most point of the occiput to the anterior-most p \\
Condyloincisive length & Head & Distance between a line connecting the posterior-most margins of the occipit \\
Condylocanine length & Head & Distance between a line connecting the posterior-most margins of the occipit \\
Braincase breadth & Head & Breadth of the braincase, excluding mastoid and paraoccipital processes \\
Zygomatic breadth & Head & Breadth across the zygomatic arches \\
Postorbital breadth & Head & Breadth at the postorbital constriction \\
Mastoid breadth & Head & Greatest breadth across the mastoid region \\
Palatal length & Head & Distance between the posterior palatal notch and the anterior border of the i \\
Maxillary toothrow length & Head & Distance from the anterior-most surface of the upper canine to the posterior- \\
Width at M1 & Head & Greatest width of palate across M1s \\
Width at M2 & Head & Greatest width of palate across M2s \\
Palatal width at canines & Head & Least width across palate between alveoli of upper canines \\
Dentary length & Head & Length between midpoint of condyle to anterior-most point of dentary \\
Mandibular toothrow length & Head & Distance from the anterior-most surface of the lower canine to the posterior-r \\
Coronoid height & Head & Perpendicular height from ventral margin of mandible to tip of coronoid proc \\
Width at mandibular condyles & Head & Greatest width between inner margins of mandibular condyles \\
\hline
\end{tabular}

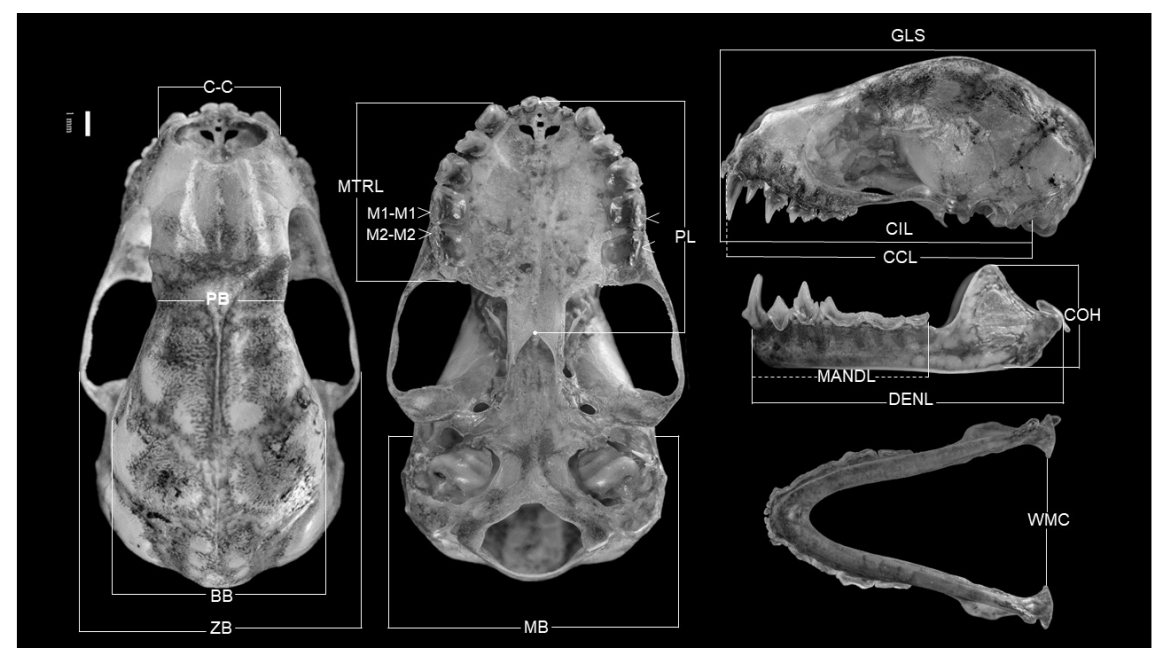

FIGURE 2 Lateral and dorsal views of the cranium and mandible (Platyrrhinus helleri, adult male), and ventral view of the cranium, measurements used in the craniodental morphometry. Abbreviations: GLS, greatest length of skull; CIL, condyloincisive length; CCL, condylocanine length; BB braincase breadth; $\mathrm{ZB}$, zygomatic breadth; $\mathrm{PB}$, postorbital breadth; $\mathrm{C}-\mathrm{C}$, palatal width at canines; $\mathrm{MB}$, mastoid breadth; PL, palatal length; MTRL, maxillary toothrow length; M1-M1, width at M1; M2-M2, width at M2; DENL, dentary length; MANDL, mandibular toothrow length; $\mathrm{COH}$, coronoid height; WMC, width at mandibular condyles.

\subsection{Statistical analyses}

Data analyses were carried out by including both fieldwork and voucher specimen's data. A linear regression was performed to assess the effects of body parameters on the changes in bite force. In the models, the averages of the bite force and body size (forearm length, greatest length of skull) and mass of each species were used. Ln $(\mathrm{y})=\beta 0+\beta 1 \mathrm{x} 1+\beta 2 \mathrm{x} 2+\varepsilon$, where $\mathrm{y}$ corresponds to the bite force, $\mathrm{x} 1$ and $\mathrm{x} 2$ are the length of the forearm and greatest length of skull, respectively. $\beta 0$ is the intercept, $\beta 1, \beta 2$ are the regression coefficients (for $\mathrm{x} 1$ and $\mathrm{x} 2$ ), and $\varepsilon$ is the random error. 
In order to analyze the intra and interspecific morphological variation, the mean \pm SD was calculated for all morphometric variables and to determine sexual dimorphism. The assumptions of normality and homoscedasticity were corroborated with the Shapiro-Wilk and Levene's test, respectively. The test results showed that our data fit a normal distribution, and accomplish the equality of variances, thus we used a two-way analysis of variance (ANOVA) to test differences between species and sexes. Post-hoc comparisons between sexes within species were performed to identify species with significant dimorphism.

To explore the differences in skull morphology and body traits among different species and sexes, we performed a Principal Component Analysis- PCA based on a correlation matrix. A threshold value of $\lambda>1$ was used to determine the relevant traits that explain most of the observed variance. Based on the preliminary results of the PCA, the variables forearm length and mass were excluded because they presented a correlation close to one, while the other variables (17) were used for the Canonical Variate Analysis- CVA. A CVA was carried out, in order to establish the largest axes of discrimination between the groups identified a priori ; find the linear combinations of the starting variables with maximum discriminating power between the groups; test whether the means of these groups along these axes are significantly different to find an ordering of the groups of individuals each represented by the vector of the means in all the variables; and to study the dimensionality of the data.

In order to determine the existence of significant variation between species and morphological traits, an analysis of variance was carried out using a generalized linear model (GLM). We used the bite force as the response variable and the cranial and body traits as covariates. The model used was: Yijks $=\mu+\mathrm{T}_{\mathrm{i}}+\delta \mathrm{j}$ $+\Omega \mathrm{k}+\varepsilon \mathrm{ijk}$, where Yijks represents the response of the bite force at the jth level of sex and ith species; $\mu$ general average, Ţi effect produced by the i-th species, $\delta \mathrm{j}$ effect produced by the j-th sex, $\Omega \mathrm{k}$ effect due to the R-th trait and عijks the random error. For detecting the masked variability, an intuitive and qualitative procedure based on graphical representation was used, then we performed post hoc tests using the Fisher's Least Significant Difference (LSD) pairwise comparison procedure. We set the statistical significance for all tests of P ? 0.05. All analyzes were performed in R 3.5.3 (R Core Team 2019).

\section{RESULTS}

Comparisons of morphological traits between males and females showed significant differences by species ( $\mathrm{F}$ $=72.04$, d.f. $=92, \mathrm{p}<0.001)$, sex $(\mathrm{F}=4.22$, d.f. $=17, \mathrm{p}<0.001)$ and their interaction $(\mathrm{F}=2.8$, d.f. $=$ $94, \mathrm{p}<0.001$, Table 2). Los rasgos craneales que presentaron mayor variabilidad fueron la longitud dentaria (DENL), la longitud de los dientes de la mandíbula (MANDL) con un coeficiente de variación de $47.2 \%$ y $18.50 \%$ respectivamente, mientras que los demás rasgos morfológicos presentaron una menor variación baja en $10 \%$.

The PCA had the first two axes explaining $91.8 \%$ of all the variance. The first component (PC1) explained $87.4 \%$ of the total variance and is determined by the width across the upper first molars (M1-M1), zygomatic breadth (ZB), forearm length (AB), dentary length (DENL) and condylo-incisor length (CIL). The second component (PC2), explained $4.4 \%$ of the variance, and was associated with the traits of maxillary toothrow length (MTRL), width between the cingulate of the upper canines (C-C), greater length of the skull (GLS), postorbital amplitude (PB), braincase breadth; (BB), and the bite force (BF) (Figure 3).

The CVA had two main groups containing species of small-sized nomadic frugivorous and sedentary frugivorous bats; and large-sized nomadic frugivorous bats. Five subgroups were identified for A. anderseniand A. phaeotis ; S. giannae ; U. convexum andPlatyrrhinus helleri ; A. planirostris ; and Artibeus lituratus (Figure 3). The traits that most contributed to the discrimination of the species in the CVA were MANDL, PL and WMC, which explained the greater morphological variation between species (Figure 4).

Table 2. Species, sample size (n) bats used to investigate bite force and jaw-skull shape relationships.

\begin{tabular}{lllllllll}
\hline Species & Sex & n & GLS & CIL & CCL & ZB & BB & PB \\
\hline A. anderseni & & 20 & $18.26(0.46)$ & $13.98(1.50)$ & $13.9(1.40)$ & $10.56(0.57)$ & $8.87(0.39)$ & 4.60
\end{tabular}




\begin{tabular}{|c|c|c|c|c|c|c|c|c|}
\hline Species & Sex & $\mathbf{n}$ & GLS & CIL & CCL & ZB & BB & PB \\
\hline & & 21 & $18.11(1.83)$ & $14.21(0.58)$ & $14.12(0.39)$ & $10.71(0.58)$ & $8.88(0.40)$ & 4.54 \\
\hline \multirow[t]{2}{*}{ A. lituratus } & & 33 & $30.69(0.74)$ & $24.35(062)$ & $23.76(0.56)$ & $18.34(0.44)$ & $14.12(0.35)$ & 6.58 \\
\hline & & 31 & $31.34(0.55)$ & $25.06(0.67)$ & $24.44(4.16)$ & $18.62(0.51)$ & $13.93(0.56)$ & 7.12 \\
\hline \multirow[t]{2}{*}{ A. planirostris } & & 26 & $27.87(4.97)$ & $22.58(0.77)$ & $22.07(0.81)$ & $16.78(0.73)$ & $13.32(0.56)$ & 6.63 \\
\hline & & 38 & $28.12(0.85)$ & $22.71(0.83)$ & $22.21(0.77)$ & $17.19(0.40)$ & $13.47(0.70)$ & 6.98 \\
\hline \multirow[t]{2}{*}{ A. phaeotis } & & 17 & $18.68(0.64)$ & $15.11(0.78)$ & $14.89(1.00)$ & $11.03(0.48)$ & $9.27(0.47)$ & 4.33 \\
\hline & & 11 & $18.33(0.77)$ & $14.21(0.58)$ & $14.24(0.52)$ & $10.71(0.41)$ & $8.95(0.39)$ & 4.45 \\
\hline \multirow[t]{2}{*}{ P. helleri } & & 9 & $21.25(0.48)$ & $17.58(0.40)$ & $17.21(0.45)$ & $10.44(0.45)$ & $8.58(0.48)$ & 4.89 \\
\hline & & 20 & $21.88(0.68)$ & $17.99(0.60)$ & $17.33(0.52)$ & $11.16(0.47)$ & $9.5(0.62)$ & 5.24 \\
\hline \multirow[t]{2}{*}{ U. convexum } & & 19 & $22.12(0.65)$ & $18.32(0.67)$ & $17.56(0.49)$ & $11.69(0.52)$ & $9.40(0.36)$ & 5.66 \\
\hline & & 21 & $22.34(0.44)$ & $17.58(0.70)$ & $17.25(0.54)$ & $11.67(0.68)$ & $10.24(0.48)$ & 5.32 \\
\hline \multirow[t]{2}{*}{ S. giannae } & & 13 & $22.25(0.62)$ & $17.81(0.69)$ & $17.22(0.63)$ & $12.09(0.34)$ & $10.45(0.26)$ & 6.08 \\
\hline & & 17 & $22.11(0.49)$ & $17.65(0.47)$ & $17.22(0.41)$ & $12.26(0.41)$ & $10.47(0.36)$ & 6.25 \\
\hline \multirow[t]{4}{*}{ Manova (Wilks) } & & & Value & Value & $\mathrm{F}$ & d.f. & $\mathrm{P}$ & \\
\hline & Specie & Specie & $5.20 \mathrm{e}-05$ & $5.20 \mathrm{e}-05$ & 72.04 & 92 & $<0.001$ & \\
\hline & Sex & Sex & 0.79 & 0.79 & 4.22 & 17 & $<0.001$ & \\
\hline & Specie*Sex & Specie*Sex & 0.39 & 0.39 & 2.8 & 94 & $<0.001$ & \\
\hline
\end{tabular}

* All measurements are presented in millimeters except for BS which are presented in Newtons.

Values are described as mean $( \pm \mathrm{SD})$.

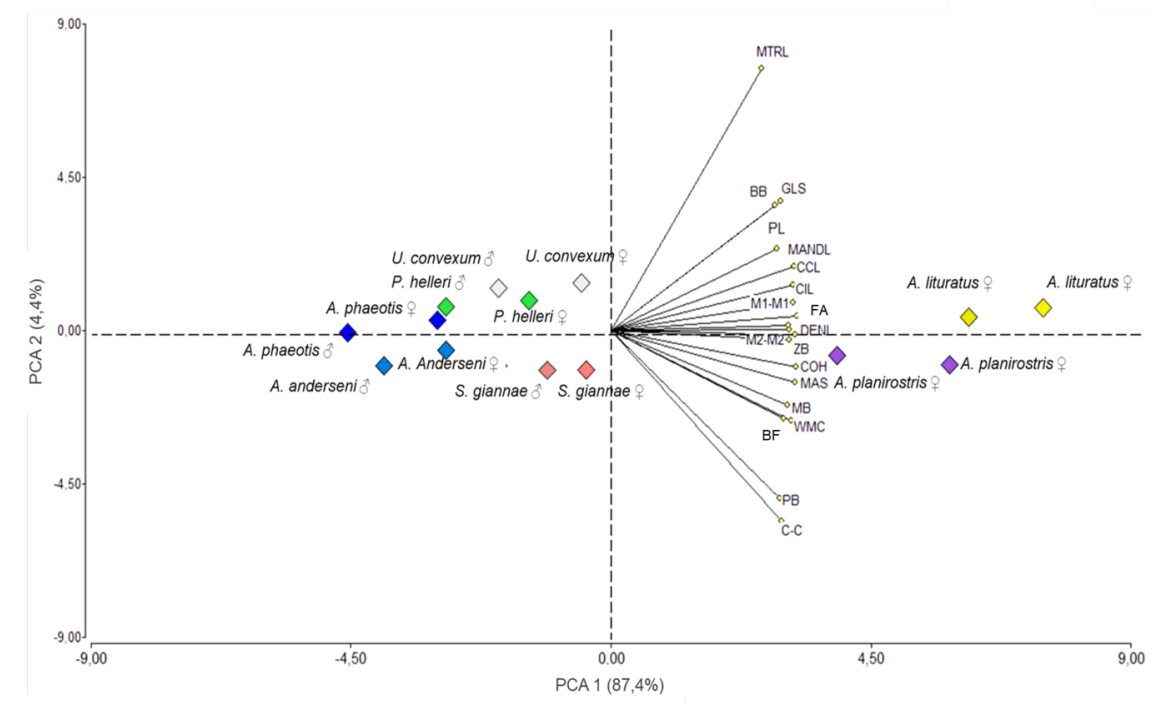

FIGURE 3 Distribution of body and craniodental traits for seven species of fruit bats based on a Principal Components Analysis (PCA).

The GLM determined significant differences both for species and for all traits $(\mathrm{F}=27.14 ; \mathrm{P}<<0.001)$ and variation between sexes $(\mathrm{F}=5.73, \mathrm{P}=0.017$; Figure 5$)$. All pairwise comparisons were significant with $\mathrm{P}$ [?] 0.01 .

\subsection{Variation in the bite force associated with craniodental traits}

Most of the variation in the bite force data according to test LSD was mainly explained for both males 
and females by the MANDL trait $(\mathrm{t}=8.00, \mathrm{df}=12, \mathrm{P}<0.01 ;$ Figure 5$)$. It was identified that 15 traits are significantly associated with a high bite force, including greatest length of the skull, condyloincisor length, condylo-canine length, postorbital breadth, mastoid breadth, zygomatic arch breadth, palatal length, mandibular toothrow length, and height of the coronoids (Table 2).

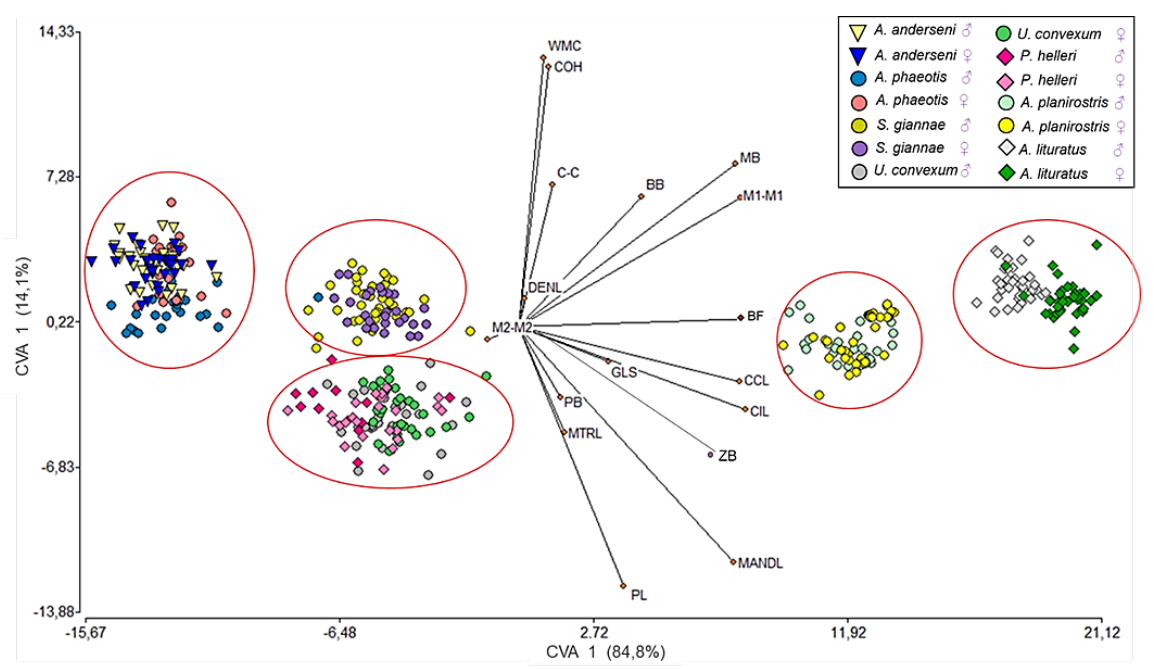

FIGURE 4 Canonical variate analysis with the description of body and craniodental traits and seven species of Stenodermatinae bats. The five ellipses (groups) are highlighted.

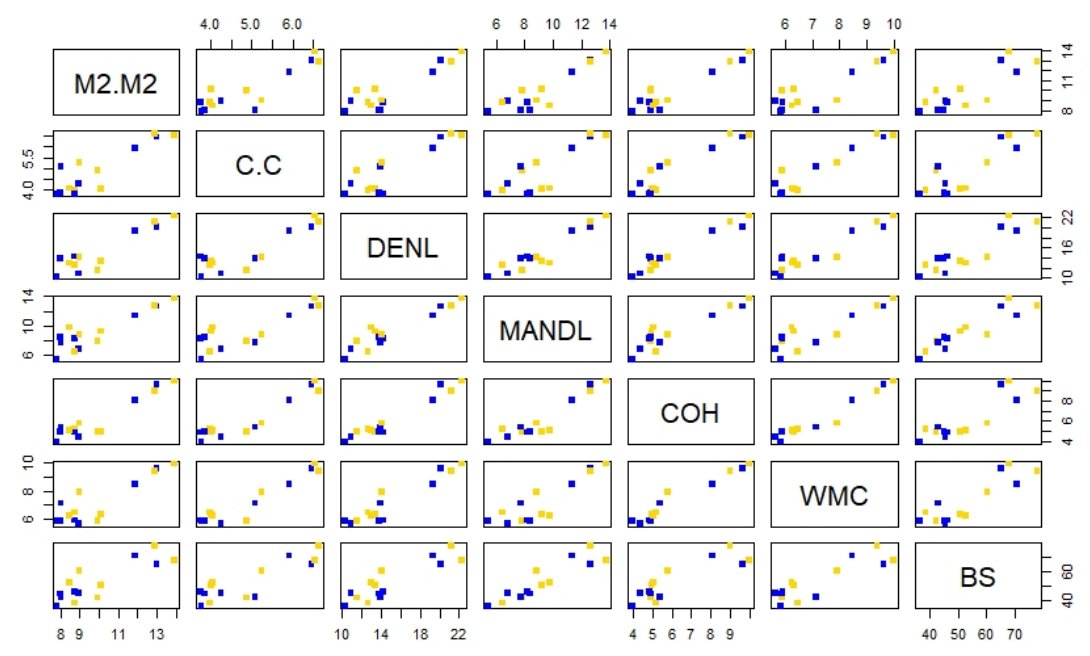

FIGURE 5 Pairwise relationships of craniodental traits with bite force for seven Colombian species of Stenodermatinae bats. Blue squares correspond to males and yellow to females. Abbreviations as in Table 1.

\subsection{Interspecific bite force variation}

The bite force varied between species; big-sized nomadic bats had the highest bite force, followed by smallsized nomadic bats ( $P$. helleri and $U$. convexum), and then by the only sedentary bat (S. giannae). 
The lowest force was recorded by small-sized nomadic bats of the species $A$. anderseni and A. phaeotis $(\mathrm{P}$ $<0.001)$. Significant intersexual differences between species were detected with the females registering a greater bite force compared to the males $(\mathrm{P}<0.04$; Figure 6$)$.
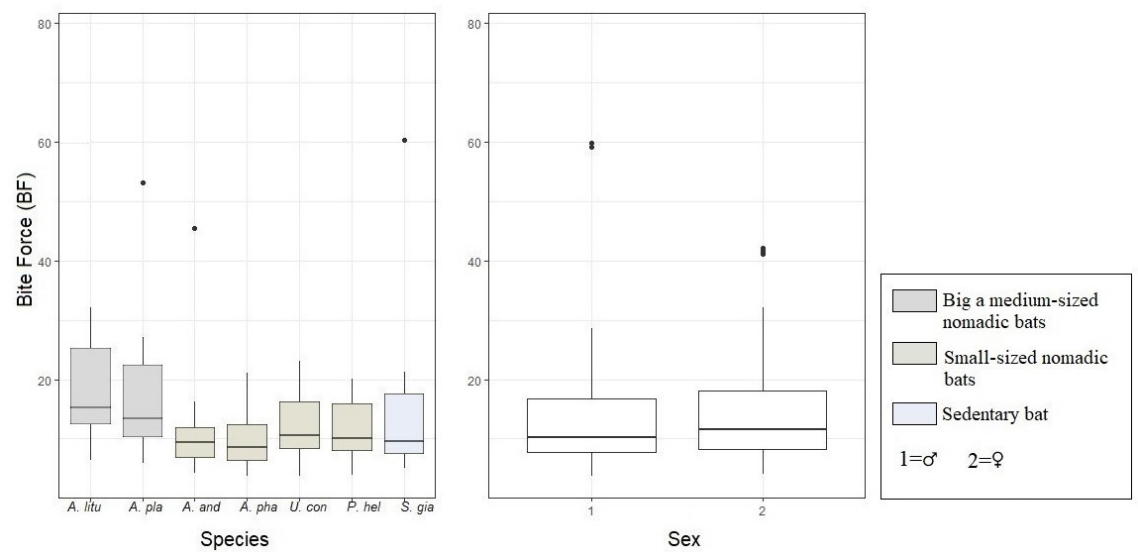

FIGURE 6 Box plot showing differences in relative bite force among bat species and sex. A. lit : Artibeuslituratus. A. pla: A. planirostris. A. and : A. anderseni. A. pha: A. phaeotis. U. con: Uroderma convexum .P. hel : Platyrrhinus helleri and S. gia: Sturnira giannae.

Our results revealed that big-sized nomadic bats, A. lituratus, and A. planirostris differed from the remaining species, as established by post-hoc tests $(\mathrm{P}<0.001)$. Furthermore, it was established that $A$. anderseni and A. phaeotis are significantly different from $S$. giannae and $U$. convexum, while these last two species are similar to P. helleri and the small species of Artibeus (Table 3).

Differences between bite force between bat species .

In this study, significant differences in skull morphology and bite strength were observed between species. LSD post-hoc testing provided clustering indicators, the first group consisted of the large nomadic bats, $A$. lituratus and $A$. planirostris; the second by a nomadic species U. convexum; the third formed by the small speciesP. helleri, S. giannae, A. pheotis and the fourth formed by A. anderseni, species that share cranial and corporal features in the third group (Table 4).

Table 3. Significance between pairs of species and relationship of bite force with other traits.

\begin{tabular}{|c|c|c|c|}
\hline Species & $\mathrm{P}$ (value significant) & Traits & $\mathrm{P}$ (value significant) \\
\hline A. lituratus - A. phaeotis & $<0,001$ & $\mathrm{Bf}-\mathrm{C}-\mathrm{C}$ & $<0,001$ \\
\hline A. lituratus - A. anderseni & $<0,001$ & $\mathrm{Bf}-\mathrm{CCL}$ & $<0,001$ \\
\hline A. lituratus $-A$. planirostris & 0,486 & $\mathrm{Bf}-\mathrm{CIL}$ & $<0,001$ \\
\hline A. lituratus - P. helleri & $<0,001$ & $\mathrm{Bf}-\mathrm{COH}$ & $<0,001$ \\
\hline A. lituratus - S. giannae & $<0,001$ & Bf - DENL & $<0,001$ \\
\hline A. lituratus - $U$. convexum & $<0,001$ & Bf - GLS & $<0,001$ \\
\hline A. phaeotis - A. planirostris & $<0,001$ & Bf - M1-M1 & $<0,001$ \\
\hline A. phaeotis - A. anderseni & 0,84 & Bf - M2-M2 & $<0,001$ \\
\hline A. phaeotis - P. helleri & 0,13 & Bf - MANDL & $<0,001$ \\
\hline A. phaeotis - S. giannae & 0,04 & Bf - MASA & $<0,001$ \\
\hline A. phaeotis - U. convexum & 0,05 & $\mathrm{Bf}-\mathrm{MB}$ & $<0,001$ \\
\hline A. planirostris - A. anderseni & $<0,001$ & Bf - MTRL & $<0,001$ \\
\hline A. planirostris - P. helleri & $<0,001$ & $\mathrm{Bf}-\mathrm{PB}$ & $<0,001$ \\
\hline A. planirostris - S. giannae & $<0,001$ & $\mathrm{Bf}-\mathrm{PL}$ & $<0,001$ \\
\hline
\end{tabular}




\begin{tabular}{llll}
\hline Species & $\mathrm{P}$ (value significant) & Traits & $\mathrm{P}$ (value significant) \\
\hline A. planirostris - U. convexum & $<0,001$ & $\mathrm{Bf}-\mathrm{WMC}$ & $<0,001$ \\
A. anderseni - P. helleri & 0,08 & $\mathrm{Bf}-\mathrm{ZB}$ & $<0,001$ \\
A. anderseni - S. giannae & 0,08 & & \\
A. anderseni - U. convexum & 0,04 & & \\
P. helleri - S. giannae & 0,99 & & \\
P. helleri - U. convexum & 0,73 & & \\
S. giannae - U. convexum & 0,73 & \\
\hline
\end{tabular}

Table 4. Post hoc test Least Significant Difference (LSD) pairwise comparison of bat species and body / cranial traits.

\begin{tabular}{ll}
\hline Species & Group \\
\hline A. lituratus & $\mathrm{a}$ \\
A. planirostris & $\mathrm{a}$ \\
U. convexum & $\mathrm{b}$ \\
P. helleri & $\mathrm{bc}$ \\
S. giannae & $\mathrm{bc}$ \\
A. pheotis & $\mathrm{bc}$ \\
A. anderseni & $\mathrm{c}$ \\
\hline
\end{tabular}

\section{DISCUSSION}

We found that skull size and inter-sex morphology was significantly different, variation that can be associated with the diet of the selected bat species; possibly as a result of differences in energy requirements during the reproductive season (de Camargo \& de Oliveira, 2012). Although sexual dimorphism has been relatively well documented in vespertilionid bats, being the females larger and heavier than males (Bornholdt, Oliveira, \& Fabian, 2008), in phylostomid bats this information is less documented despite it being the most diverse and distributed family in the Neotropics (Gardner 2008). However, López-Aguirre \& Pérez-Torres (2015) identified that Artibeus lituratus females in Colombia had greater fluctuating asymmetry in the splanchnocranium presenting a differential on bite force.

\subsection{Variation in the bite force associated with craniodental traits}

Bite force has been established as an important performance trait for vertebrates that is associated with both cranial morphology and trophic ecology (Santana, Dumont, \& Davis, 2010). However. studies in bats have based their conclusions on biomechanical models of the bite force without adequately testing the assumed correlation of it with the shape of the skull (Aguirre, Herrel, Van Damme, \& Matthysen, 2002; Dumont, 2007; Herrel, De Smet, Aguirre \& Aerts, 2008). Our study shows, for the first time, strong quantitative evidence of such a correlation by using a dataset of cranial traits involved in bite force within a morphologically diverse clade of New World fruit bats.

\subsection{Interspecific bite force variation}

Stenodermatinae represents a subfamily of Phyllostomidae bats with a diet that contains significantly more fruit than other family's bats (Santana, Grosse, \& Dumont, 2012). They are morphologically diverse with cranial and mandibular traits that overlap with other feeding guilds (Santana, Grosse, \& Dumont, 2012), which is reflected in the variety of foods as well as in the tendency of these species to specialize in a group of particular fruits (Rojas, Vale, Ferrero, \& Navarro, 2012; Rossoni, Assis, Giannini, \& Marroig, 2017). Several craniodental traits contribute to generate a greater bite force and the differences between these particular traits had showed a clear segregation between the species (Santana, Grosse, \& Dumont, 2012). 
The association in craniodental features and bite force by species can be explained by the type of fruit consumed. A. phaeotis, P. helleri and S. giannae (small-sized and sedentary nomadic fruit bats) formed an independent group. These species have a short skull and a shorter distance from the teeth to the jaw joint, which allows them to consume hard and soft fruits (Dumont et al., 2012), P. helleri and S. giannae are characterized by elongated and narrow snouts (Santana, Grosse, \& Dumont, 2012), which is associated with the consumption of soft and smaller fruits such as those of Solanaceae (Arias \& Pacheco, 2019; García-Herrera, Ramírez-Fráncel and Flórez, 2019). Species that share cranial and nutritional traits with $D$. anderseni. For its part, Uroderma convexum was distinguished from the other species studied here by having a parallel rostrum and a short face that abruptly expands from the apex to the edges of the lacrimal bone (MantillaMeluk, 2014). These characteristics allow them to exploit mainly hard fruits of plant species such as Ficus spp. (Sagot and Stevens, 2012).

All the big and small-sized nomadic frugivorous bat species studied here, except for $A$. anderseni and $A$. phaeotis had a stronger bite force, which was correlated to a greater length of the skull, shorter palate, narrower width between molars, dentary length, and higher coronoid process. These traits have been recognized as predictors of a biomechanical advantage for higher feeding performance (Dumont et al., 2012). Shortening and widening of the rostrum in A. anderseni and A. phaeotis was negatively correlated to bite force, although it should confer a greater biomechanical advantage; a pattern that has been repeatedly observed in placental and marsupial carnivores (Wroe \& Milne, 2007). This is probably due to the fact that the variation in size could be the most dominant factor and it has been shown that the differential proportions of the skull determine the maximum value of the bite force (Herrel, Podos, Huber, \& Hendry, 2005; Nogueira et al., 2009; Dollion et al., 2016). Recent studies have suggested that among closely related mammals, larger taxa exhibit relatively longer faces, whereas smaller taxa exhibit paedomorphic traits such as proportionally shorter faces and larger brains (Cardini \& Polly, 2013; Cardini, Polly, Dawson, \& Milne, 2015; Tamagnini, Meloro, \& Cardini, 2017). This pattern called cranial evolutionary allometry, has been seen in antelopes, squirrels, fruit bats, cats and kangaroos (Tamagnini, Meloro, \& Cardini, 2017).

Previous studies have demonstrated that skull size is important in determining interspecific differences in bite force, specifically, Nogueira, Peracchi \& Monteiro (2009) found that, in phyllostomids, size-corrected bite forces were correlated with shorter rostra, alignment of the molars along the masseter insertion region, and expansion of the anterior zygomatic arch and angular process. On the contrary, our study determined that the variation in bite force in Stenodermatinal bats is better explained by the length of the skull, condyloincisor, condylo-canine, mandibular toothrow and height of the coronoid, results similar to those reported by Herrel et al.,(2008) in a sample of bat species (including non-phylostomids).

Shortening and widening of the rostrum in A. anderseni and A. phaeotis was negatively correlated to bite force, although it should confer a greater biomechanical advantage; a pattern that has been repeatedly observed in placental and marsupial carnivores (Wroe \& Milne, 2007). This is probably due to the fact that the variation in size could be the most dominant factor and it has been shown that the differential proportions of the skull determine the maximum value of the bite force (Herrel, Podos, Huber, \& Hendry, 2005; Nogueira et al., 2009; Dollion et al., 2016). Recent studies have suggested that among closely related mammals, larger taxa exhibit relatively longer faces, whereas smaller taxa exhibit paedomorphic traits such as proportionally shorter faces and larger brains (Cardini \& Polly, 2013; Cardini, Polly, Dawson, \& Milne, 2015; Tamagnini, Meloro, \& Cardini, 2017). This pattern called cranial evolutionary allometry, has been seen in antelopes, squirrels, fruit bats, cats and kangaroos (Tamagnini, Meloro, \& Cardini, 2017).

Another factor that could explain our results is that bats modulate the force of the bite according to the exploited resources of soft and hard food (Santana \& Dumont, 2009). Artibeus vary in the size and texture of the fruits they prefer (Wendeln, Runkle, \& Kalko, 2000) and may exhibit differential maximum bite force, which can potentially increase by more than $10 \%$ when consuming hard fruits (Santana \& Dumont, 2009). Another factor to consider is the possible variation in the intraspecific bite force in response to the temporal or geographical variation of food resources or the hormonal status of bats, as proposed by Irschick et al. (2006). Since the bats included in our study are composed of individuals from different localities and data 
(fieldwork and voucher specimens; Appendix I), our data could be susceptible to this source of variation and therefore a more detailed study is needed to test this hypothesis and further improve our understanding of the relationships of bite force and craniodental traits.

Given that nomad bats consume similar fruits, they could require the same force to process, so we expected that all bats grouped in this category would present similar bite forces, however our results established that the species Artibeus lituratus, A. planirostris, followed U. bilobatum and P. hellerirecorded the highest bite force, probably because these bats feed on food resources that clearly have different mechanical demands when consuming even other resources other than the fruits.

All Stenodermatinae are frugivores with short and wide rostrum, but our results show that can occur some divergent morphologies within the clade, which is seen in the large number of species within the subfamily and highly diverse genera (Murillo-Garcia \& De la Vega, 2018). As has been documented in other vertebrates, closely related species exhibit strong positive relationships between large skulls and greater biomechanical advantage (Maestri et al., 2016; Santana \& Miller, 2016). Our findings illustrate that skull size is a determining factor in the bite force and emphasizes that the use of functional traits is relevant to establishing the feeding performance of bat species. This highlights the importance of studying the relationships between morphology, bite force and the ecology of the species to get a better understanding of evolutionary adaptions of highly diverse Neotropical bat groups.

\section{Acknowledgements}

The authors wish to thank the staff of the Research Group in Zoology (GIZ), Universidad del Tolima (Ibague, Colombia). LAR-F and LVG-H thank the Convocatoria No. 755, 2016 para la Formacion de Capital Humano de Alto Nivel para el Departamento del Tolima, Colfuturo (miniciencias) and Departamento del Tolima for support (doctoral scholarships). We thank the biologists Emmanuel Quintero, David Santiago Varon, Carlos Guzman and Benjamin Polanco for their support during the field activities and the people from each of the localities surveyed for their hospitality. Specimens collected are covered through the "Permiso Marco de Recoleccion" granted to the Universidad del Tolima (Resolucion No. 2191. November 27, 2018. Autoridad Nacional de Licencias Ambientales-ANLA). We thank Dr Jairo Perez for allowing access to the voucher specimens of the Museo Javeriano de Historia Natural "Lorenzo Uribe, SJ".

\section{Authors' contributions}

L.V.G-H., S.L.P. conceived the ideas and designed methodology; L.V.G-H., L.A.R-F established the activities in the field, developed the methodology and took the craniodental measurements in the different collections and museums evaluated; A.S-H., L.V.G-H., L.A.R-F and S.L.P. analyzed the data; B.L, G.G and G.R-F. led the writing of the manuscript. All authors contributed critically to the drafts and gave final approval for publication.

\section{Data Accessibility}

The data are available athttps://datadryad.org/stash/share/N6vW4UGTQZbdh132I0gaPR2GYsa4iDCy5YdsEeNaerM

\section{REFERENCES}

Aguirre LF. Herrel A. Van Damme R. Matthysen E. 2002. Ecomorphological analysis of trophic niche partitioning in a tropical savannah bat community. Proceedings of the Royal Society B. 269:1271. https://doi.org/10.1098/rspb.2002.2011.

Aguirre. L. F., Herrel, A., Van Damme R., \& Matthysen, E. (2003). The implications of food hardness for diet in bats. Functional Ecology, 17, 201-212.

Arias, E., \& Pacheco, V. (2019). Dieta y estructura trofica de un ensamblaje de murcielagos en los bosques montanos del Santuario Nacional Pampa Hermosa. Junin. Peru. Revista Peruana de Biologia ,26 , 169-182. http://dx.doi.org/10.15381/rpb.v26i2.16375 
Bels, V., \& Herrel, A. (2019). Feeding. a Tool to Understand Vertebrate Evolution Introduction to "Feeding in Vertebrates". In Bels, V. \& Whishaw, I. Q. (Ed.), Feeding in Vertebrates: Evolution. Morphology (pp.118). Berlin, Germany: Springer.

Bornholdt, R., Oliveira, L. R. D., \& Fabian, M. E. (2008). Sexual size dimorphism in Myotis nigricans (Schinz, 1821) (Chiroptera: Vespertilionidae) from south Brazil. Journal of Biology ,68 , 897-904. http://dx.doi.org/10.1590/S1519-69842008000400028

Cardini, A., \& Polly, P. D. (2013). Larger mammals have longer faces because of size -related constraints on skull form. Nature communications , 4, 2458.

Cardini, A., Polly, D., Dawson, R., \& Milne, N. (2015). Why the Long Face? Kangaroos and Wallabies Follow the Same "Rule" of Cranial Evolutionary Allometry (CREA) as Placentals. Evolutionary Biology, 42 , 169-176. http://dx.doi.org/10.1007/s11692-015-9308-9

Cisneros, L. M., Fagan, M. E., \& Willig, M. R. (2015). Effects of human-modified landscapes on taxonomic, functional and phylogenetic dimensions of bat biodiversity. Diversity and Distributions, 21, 523-533. https://doi.org/10.1111/ddi.12277

de Camargo, N. F., \& de Oliveira, H. F. (2012). Sexual dimorphism inSturnira lilium (Chiroptera. Phyllostomidae): can pregnancy and pup carrying be responsible for differences in wing shape? Plos one , 7 , e49734. http://dx.doi.org/10.1371/journal.pone.0049734

Dietz, C., Dietz, I., \& Siemers, B. M. (2007). Growth of horseshoe bats (Chiroptera: Rhinolophidae) in temperate continental conditions and the influence of climate. Mammalian Biology, 72 , 129-144.

Dollion, A. Y., Measey, G. J. Cornette, R., Carne, L., Tolley, K. A., Silva, J. M., da. Boistel, R., Fabre, A. C., \& Herrel, A. (2017). Does diet drive the evolution of head shape and bite force in chameleons of the genus Bradypodio n? Functional Ecology , 31 , 671-684. https://doi.org/10.1111/1365-2435.12750

Dumont. E. R. (2007). Feeding mechanisms in bats: variation within the constraints of flight. Integrative and Comparative Biology,47 , 137-146. https://doi.org/10.1093/icb/icm007

Dumont, E. R. \& O'Neil, R. (2004). Food hardness and feeding behavior in old world fruit bats (Pteropodidae). Journal Mammal ,85, 110-116. https://doi.org/10.1644/BOS-107

Dumont, E. R., Herrel, A., Medellin, R. A., Vargas-Contreras, J. A., Santana, S. E. (2009). Built to bite: cranial design and function in the wrinkle-faced bat. Journal of Zoology , 279 , 329-337. https://doi.org/10.1111/j.1469-7998.2009.00618.x.

Dumont, E. R., Davalos, L. M., Goldberg, A., Santana, S. E., Rex, K., Voigt, C. C. (2012). Morphological innovation. diversification and invasion of a new adaptive zone. Proceedings of the Royal Society B , 279 , 1797-1805. https://doi.org/10.1098/rspb.2011.2005.

Freeman, P. W., \& Lemen, C. A. (2008). Measuring bite force in small mammals with a Piezo-resistive sensor. Journal Mammalogy,89 , 513-517. https://doi.org/10.1644/07-MAMM-A-101R.1.

Garcia-Morales, R., Moreno, C. E., Badano, E. I., Zuria, I., Galindo-Gonzalez, J., Rojas-Martinez, A. E., \& Avila-Gomez, E. S. (2016). Deforestation impacts on bat functional diversity in tropical landscapes. PloS one , 11, e0166765. https://doi.org/10.1371/journal.pone.0166765

Garcia-Herrera, L. V., Ramirez-Francel, L. A. R., \& Florez, G. R. (2019). Consumo de plantas pioneras por murcielagos frugivoros en un fragmento de bosque seco tropical (Colombia). Ciencia en desarrollo, 10 , $22-31$.

Giannini, N. P., \& Kalko, E. K. V. (2004). Trophic structure in a large assemblage of phyllostomid bats in Panama. Oikos , 2 , 209-220. https://doi.org/10.1111/j.0030-1299.2004.12690.x 
Herrel, A., Podos, J., Huber, S. K., \& Hendry, A. P. (2005). Bite performance and morphology in a population of Darwin's finches: implications for the evolution of beak shape. Functional Ecology ,19 , 43-48. https://doi.org/10.1111/j.0269-8463.2005.00923.x

Herrel, A., De Smet, A., Aguirre, L. F., \& Aerts, P. (2008). Morphological and mechanical determinants of bite force in bats: do muscles matter? Journal of Experimental Biology , 211 , 86-91. https://doi.org/10.1242/jeb.012211

Irschick, D. J., Ramos, M., Buckley, C., Esltrot, J., Carlisle, E., Lailvaux, S. P., Bloch, N., Herrel, A., \& Vanhooydonck, B. (2006). Are morphology-performance relationships invariant across different seasons? A test with the green anole (Anolis carolinensis ). Oikos ,114 , 49-59. https://doi.org/10.1111/j.2006.00301299.14698.x

Lopez-Aguirre, C., \& Perez-Torres, J. (2015). Cranial and mandibular asymmetry in Artibeus lituratus (Chiroptera. Phyllostomidae) from Colombia. Universitas Scientiarum , 20 , 141-152.

Maestri, R., Monteiro, L. R., Fornel, R., Upham, N. S., Patterson, B. D., \& de Freitas, T. R. O. (2017). The ecology of a continental evolutionary radiation: Is the radiation of sigmodontine rodents adaptive? Evolution , $71,610-632$.

Manhaes, I. A., Nogueira, M. R., \& Monteiro, L. R. (2017). Bite force and evolutionary studies in phyllostomid bats: a meta-analysis and validation. Journal of Zoology, 302(4), 288-297. https://doi.org/10.1111/jzo.12457

Mantilla-Meluk, H. (2014). Defining species and species boundaries in Uroderma (Chiroptera: Phyllostomidae) with a description of a new species. Occasional Papers Museum of Texas Tech University , 325 , $1-25$.

Murillo-Garcia, O. E., \& De la Vega, M. E. (2018). Divergence. convergence and phenotypic diversity of neotropical frugivorous bats.Diversity , 10 , 10-12. https://doi.org/10.3390/d10030100

Nogueira, M. R., Peracchi, A. L., \& Monteiro, L. R. (2009). Morphological correlates of bite force and diet in the skull and mandible of phylostomid bats. Functional Ecology , 23 , 715-723. https://doi.org/10.1111/j.1365-2435.2009.01549.x

Reid, J. L., Mendenhall, C. D., Zahawi, R. A., \& Holl, K. D. (2015). Scale-dependent effects of forest restoration on Neotropical fruit bats.Restoration Ecology , 23 , 681-689. doi: https://doi.org/10.1111/rec.12235

Rojas, D., Vale, A., Ferrero, V., \& Navarro, L. (2012). The role of frugivory in the diversification of bats in the Neotropics.Journal Biogeography , 39 . 1948-1960. https://doi.org/10.1111/j.1365-2699.2012.02709.x

Rossoni, D. M., Assis, A., Giannini, N. P., \& Marroig, G. (2017). Intense natural selection preceded the invasion of new adaptive zones during the radiation of New World leaf-nosed bats. Scientific Reports , 7 , $1-11$.

Core Team. (2019). R: A language and environment for statistical computing .Vienna, Austria: R Foundation for Statistical Computing.

Sagot, M, \& Stevens, R. (2012). The evolution of group stability and roost lifespan: perspectives from tent-roosting bats. Biotropica, 44 , 90-97.

Santana, S. E., \& Dumont, E. R. (2009). Connecting behaviour and performance: the evolution of biting behaviour and bite performance in bats. Journal of Evolutionary Biology , 22 , 2131-2. https://doi.org/10.1111/j.1420-9101.2009.01827.x

Santana, S. E., Dumont, E. R., \& Davis, J. L. (2010) Mechanics of bite force production and its relationship to diet in bats. Functional Ecology, 24, 776-784. https://doi.org/10.1111/j.1365-2435.2010.01703.x. 
Santana, S. E., Grosse, I. R., \& Dumont, E. R. (2012). Dietary hardness. loading behavior. and the evolution of skull form in bats.Evolution , 66 , 2587-2598. https://doi.org/10.1111/j.1558-5646.2012.01615.x

Santana, S. E., \& Miller, K. (2016). Extreme postnatal scaling in bat feeding performance: a view of ecomorphology from ontogenetic and macroevolutionary perspectives. Integrative and Comparative Biology , 56 , 459-468. https://doi.org/10.1093/icb/icw075

Sikes, R. S., \& Animal Care and Use Committee of the American Society of Mammalogists. (2016). Guidelines of the American Society of Mammalogists for the use of wild mammals in research and education. Journal of mammalogy , $97,663-688$.

Soriano. P. 2000. Functional structure of bat communities in tropical rainforests and Andean cloud forests. Ecotropicos , 13 , 1-20.

Shi, B., Wang, Y., Gong, L., Chang, Y., Liu, T., Zhao, X., Lin, A., Feng, J, \& Jiang, T. (2020). Correlation of skull morphology and bite force in a bird-eating bat (Ia io ; Vespertilionidae).Frontiers in Zoology , 17 , 1-14. https://doi.org/10.1186/s12983-020-00354-0

Tamagnini, D., Meloro. C., \& Cardini, A. (2017). Anyone with a Long-Face? Craniofacial Evolutionary Allometry (CREA) in a Family of Short-Faced Mammals, the Felidae. Evolutionary Biology ,44, 476-495. https://doi.org/10.1007/s11692-017-9421-z

Thiagavel, J., Cechetto, C., Santana, S. E., Jakobsen, L., Warrant, E. J., \& Ratcliffe, J. M. (2018). Auditory opportunity and visual constraint enabled the evolution of echolocation in bats. Nature communications , 9 , 1-10. https://doi.org/10.1038/s41467-017-02532-x

Wendeln, M. C., Runkle, J. R., \& Kalko, E. K.V. (2000). Nutritional values of 14 fig species and bat feeding preferences in Panama.Biotropica, 32, 489-501. https://doi.org/10.1111/j.1744-7429.2000.tb00495.x

Wroe, S., \& Milne, N. (2007). Convergence and remarkably consistent constraint in the evolution of carnivore skull shape. Evolution , 61, 1251-1260. https://doi.org/10.1111/j.1558-5646.2007.00101.x

\section{APPENDIX I. SPECIMENS EXAMINED}

The following list includes all specimens examined in this study, with their respective localities.

Artibeus anderseni (41)- AMAZONAS, Leticia (ROM 53614, 53615, 53616, 63061) ANTIOQUIA, Los Remedios (ROM 84982), CUNDINAMARCA, La Gran Curva, $114 \mathrm{~km}$ al oeste de Bogota (ROM 48959, 51790), Melgar (ROM 53613, 75300, 75302), Puerto Salgar (ROM 44956, 44957, 44965) TOLIMA, Alvarado, vereda Rincon de Chipalo, Parque Nacional del Arroz (CZUT-M 2089, 2090, 2091, 2099, 2100), Armero Guayabal, Centro Universitario Regional del Norte - Universidad del Tolima (ROM 1128, 1415, 1416, 1418, 1434, 1436, 1481, 1492, 1515, 1516, 1517, 1536 ,1537, 1538, 1541, 1624, 1638, 1639, 1641, 1642), Espinal (ROM 88089), Ibague, vereda Aparco (CZUT-M 2098, 2103).

Artibeus lituratus (64)- CAUCA, Bellavista (ROM 63232, 63063, 64066, 64067, 64068, 64069, 64070, 64071, 67247, 67253, 67255, 67256, 67261), CUNDINAMARCA, Puerto Salgar (ROM 44811), META, Villavicencio, Puerto Lopez (ROM 88083), TOLIMA, Ambalema, vereda Chorrillo (CZUT-M 1410, 1546, 1567, 1569, 1668), Armero Guayabal, Centro Universitario Regional del Norte - Universidad del Tolima (CZUT-M 1124, 1413, 1545, 1546, 1564, 1565, 1566, 1596, 1628, 1629, 1631, 1704), Ibague, vereda Chucuni (CZUT-M 0763, 0764, 0766, 0835), Buenos Aires (ROM 44882, 44885), Melgar, Santo Tomas (MUJ 00826, 00827, 00828, 00829, 00830, 00832, 00833, 00834) Suarez, vereda Batatas (CZUT-M 0299, 0301, 0303, 0305, 0344, 0346), vereda Aguas Claras (CZUT-M 0363), vereda Los Arrayanes (CZUT-M 1230, 1231), PUTUMAYO, vereda Guascayaco (ROM 46356, 49206, 49209, 49211), VAUPES, Mitu (ROM 45258, 45259, 45260), VALLE DEL CAUCA (ROM 44889, 44890).

Artibeus planirostris (75)- META, Fuente de Oro, Km 9 Carretera Puerto Limon (ROM 90109, 91409), TOLIMA, Ambalema, vereda Chorrillo (CZUT-M 1468, 1469, 1470, 1471, 1472, 1473, 1474, 1475, 1476, $1477,1494,1544,1568,1583,1584,1585,1586,1587,1588,1589,1590,1591,1592,1599,1600,1605$, 
1632, 1643, 1644, 1645, 1646, 1669, 1670, 1671, 1672, 1673, 1695, 1696, 1697, 1699, 1700, 1701), Ibague, vereda Aparco (CZUT-M 1994, 1995, 1996), Armero Guayabal, Centro Universitario Regional del Norte Universidad del Tolima (CZUT-M 1412, 1414, 1493, 1513, 1514, 1542, 1543, 1593, 1594, 1595, 1598, 1698, 1705, 1712, 2008, 2049), Suarez, vereda Batatas (CZUT-M 0243, 0244, 0245, 0298, 0300, 0302, 0304, 0345, 0347, 2070), PUTUMAYO, vereda Guayaco (ROM 49211), Vereda San Miguel (67246).

Artibeus phaeotis (28)- AMAZONAS, Leticia (ROM 53610, 53611, 53612), CAUCA, Bellavista (ROM 64064, 64059, 64057), MAGDALENA, Santa Marta (ROM 79885), TOLIMA, Alvarado, vereda Rincon de Chipalo, Parque Nacional del Arroz (CZUT-M 2106), Ambalema, vereda Chorrillo (CZUT-M 1346, 1549, 1572, 1647) Armero Guayabal, Centro Universitario Regional del Norte - Universidad del Tolima (CZUT-M 1127, 1435, 1437, 1518, 1571, 1625, 1640, 1702, 1703, 1706, 1710, 1711), Mariquita (MUJ 0269, 0285, 0286), Melgar (MUJ 00835).

Platyrrhinus helleri (31) -MAGDALENA, Santa Marta (ROM 79882), TOLIMA, Alvarado, vereda Rincon de Chipalo, Parque Nacional del Arroz (CZUT-M 2009, 2062), Ambalema, vereda Chorrillo (CZUT-M 1709), Armero Guayabal, Centro Universitario Regional del Norte - Universidad del Tolima (CZUT-M 1539, 1547, 1570, 1602, 1626, 1630, 2010), Libano, Hacienda La Trinidad (ROM 88082), Ibague, vereda Martinez (CZUTM 0027, 0116), San Sebastian de Mariquita (CZUT-M 1063, 1065, 1072), Melgar (CZUT-M 1928), vereda Santo Tomas (MUJ 00837, 00838, 00839, 00841), Suarez, vereda Batatas (CZUT-M 0341, 0364, 1914), PUTUMAYO (ROM 403559, 46375, 46353, 63239), VAUPES, Mitu (ROM 45274, 45273),

Uroderma convexum (40)- MAGDALENA, Santa Marta (ROM 79886), TOLIMA, Alvarado, vereda Rincon de Chipalo, Parque Nacional del Arroz (CZUT-M 2093, 2101, 2104, 2105), Armero Guayabal, Centro Universitario Regional del Norte - Universidad del Tolima (CZUT-M 1126, 1438, 1511, 1512, 1540, 1597, 1601, 1622, 1623, 1633, 1634, 1635, 1636, 1637, 1694, 1707), Ibague, vereda Aparco (CZUT-M 2095, 2096, 2097, 2102), San Sebastian de Mariquita (CZUT-M 1054, 1070), Melgar (CZUT-M 1927, MUJ 00842, 00843, 00844, ROM 62508), Suarez, vereda Batatas (CZUT-M 1915), PUTUMAYO, vereda Guascayaco (ROM 46360), vereda Horno (ROM 63240, 63240), VAUPES, Mitu (CZUT-M 45268, 45267, 45366, 45265).

Sturnira giannae (30)- TOLIMA, Ambalema, vereda Chorrillo (CZUT-M 1116, 1117, 1118, 1296, 1310, 1318, 1342, 1343), Armero Guayabal, Centro Universitario Regional del Norte - Universidad del Tolima (CZUT-M 1129, 1403), Ibague, vereda Aparco (CZUT-M 2014, 2015, 2016, 2021, 2022, 2023, 2028), Mariquita (CZUTM 1056, 1061), Suarez, vereda Batatas (CZUT-M 0234, 0246, 0307, 0362, 1236), PUTUMAYO (ROM 40374, 40313, 40349, 40375, 46373, 49184). 